\title{
Spatial Analysis of Rural Medical Facilities Using Huff Model: A Case Study of Lankao County, Henan Province
}

\author{
Pengyan Zhang ${ }^{1,2}$,Xing Ren ${ }^{3}$, Qianqian Zhang ${ }^{1}$, Jianjian $\mathrm{He}^{1}$ and Yongmin Chen ${ }^{1 凶}$ \\ ${ }^{1}$ College of Environment and Planning, Henan University, Kaifeng, China \\ ${ }^{2}$ Labrary of Global Change Ecology, Henan University, Kaifeng, China \\ ${ }^{3}$ Oya International School, Henan University, Kaifeng, China \\ email: pengyanzh@126.com; \\ ${ }^{\otimes}$ Corresponding author email: youminchen@ $@$ henu.edu.cn
}

\begin{abstract}
Rural health care reformed in the new situation in China, indicating that the construction of medical facilities not only to solve difficult medical problems, but also to take into account the efficiency and fairness of the use of medical resources allocation. Facing these problems, the paper aims to assess the spatial distribution of rural medical services by using geographic information systems (GIS) and spatial accessibility indexes. Lankao County in Henan Province and 21 hospitals of township and county are selected as study samples. First adopted ArcGIS10.0 to collate data. Second, the authors established a network dataset to analysis the maximum coverage for hospital services space accessibility. At last, established Huff model and built a scientific evaluation for the current hospitals' distribution. There are several findings from the case study. First, the distribution of medical facility is unbalanced in rural areas in term of per capita, such as opportunity for assessing medical services and the convenience of utilizing medical services. Second, by using the Huff Model to calculate the potential population in service regions, the Huff Model to calculate the potential population in service regions, the results showed the low efficiency of the use of medical resources and the problems in these regions.
\end{abstract}

Keywords:Component: Medical facility, Huff Model, Lankao County, Geographic Information System (GIS)

\section{Introduction}

The survey of medical equity conducted by the World Health Organization indicates that China ranked the fourth from the bottom among 191 member countries [1]. The equity of medical provision is one of the most important objectives in China's healthcare and medical system reforms [2]. However, the geospatial issues, such as healthcare facility site-selection, spatial accessibility, and resource allocation, are not fully explored in healthcare and medical planning by local authorities.

GIS, providing powerful capabilities of spatial analysis and modeling, is an emerging technology for healthcare management, analysis and decision making. For example, it has been successfully applied in emergency services management and scheduling [3-5]. Emergencies can happen at any place, any time, in any way. The key purpose of the emergency medical care system (EMCS) is to save lives, to minimize the damage of personal health, and to ensure the quality of life as much as possible. Network analysis can be carried out to provide the shortest path of the ambulance service and rapid response decision-making. GIS is also an effective tool in public health monitoring and assessment, disease mapping and spatial dissemination modeling [6,7].

This paper aims to evaluate the spatial equity and efficiency of medical facilities from geospatial perspective using GIS and Huff model. The findings will benefit the medical facility planning. 


\section{The Study Area and Data}

Lankao County, Henan province, an agriculture county, is located between east $114^{\circ} 40$

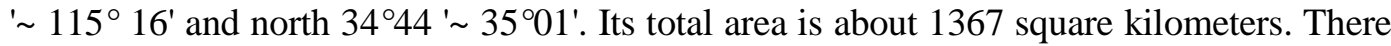
are about 0.75 million people. There are 2015 beds in all hospitals whose level is above township hospital. The number of health workers is 3142, and the number of practicing physicians is 625 . Housing construction area is 101700 square meters, and the number of medical equipment whose price is the million or more is 328 .

These data were obtained from the field survey and the digital proccessing:

(1) The electronic map of Lankao County boundary

(2) The electronic map of the villages' population distribution in Lankao County

(3) The electronic traffic map of Lankao County

(4) The electronic map of Hospital distribution in Lankao County

All data are showed in Figure1.

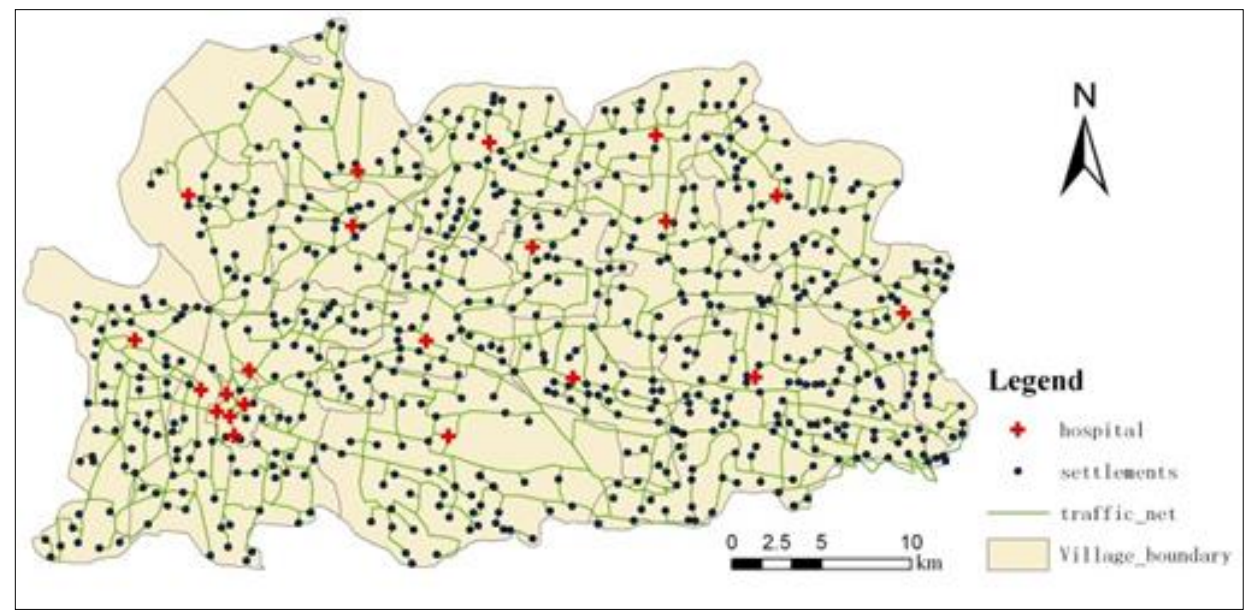

Figure 1: The Distributions of Hospitals and Settlements

To improve the accuracy of this study, we collected more data, such as the number of technical staff, the number of hospital bed and the number of large medical equipment of each hospital in Lankao County, and information from the investigation from local authorities. These data were made out for connecting the spreadsheet and corresponding layer's attribute table to avoid complex operations of the research process.

\section{Creating Network Dataset}

The study area of this paper is the entire Lankao county's medical facilities and services, a wide range, led to when building the road network dataset this paper ignored the road steering and grades and other issues, using walking distance as a cost index for evaluation.

First, built Lankao County spatial data sets, imported the collected map data into the dataset by Import tool, found the same property columns in both various layers of existing maps and the statistical tables, used the Join tool in Arcgis to make the link and to save. Then created a network dataset by following these steps:

(1). Click Start> All Programs> ArcGIS> ArcCatalog 10 start ArcCatalog.

(2). Navigate to the location of Lankao County dataset in the directory tree,.

(3). Right-click the network dataset, and then click Buildis.

(4). Click Next, select the Lankao line layer.

(5). Click Next, then click connectivity to enter the choice set of the connection properties Any Vertex (any node connectivity). 
(6). Continue to click Next until you set the spending properties, click add, enter "length" in name, select "meters" for units. And set the length of the property type as "field", value means the path length.

(7). Click Next until the network dataset is completed.

\section{Methodology and Computing}

Huff model [8] was first used in the field of business. In the face of a number of commercial outlets in the area, the probability of each network residents choose is different. The size of this probability is determined by the size of commercial outlet and the distance of residents to this outlet. By the Huff model calculation, we can draw the probabilities of customers choosing each shop, which provide the basis for the operator's business strategy. The expression is shown as Formula 1.

$$
P_{i j}=\left(S_{j} / T_{i j}{ }^{n}\right) / \sum\left(S_{j} / T_{i j}{ }^{n}\right)
$$

In the formula (1): $P_{i j}$ stands for the probability of the customers of region $i$ to store $j . S_{j}$ stands for the scale of store $j . T_{i j}$ stands for the distance or the time it takes from the customers of region $i$ to store $j$. The $n$ as the effect index, if $t$ stands for the time, $n=1$, and if $t$ stands for the distance, $n=2$.

The Huff model specific to the study of rural health facilities space layout in this paper is established as Formula 2 and Formula 3.

$$
\begin{aligned}
& A_{i j}=\sum_{j} \frac{\alpha_{j} S_{j}}{d_{i j}^{\beta}} \\
& \boldsymbol{P}_{i j}=\frac{\boldsymbol{A}_{i j}}{\sum_{j=1}^{n} \boldsymbol{A}_{i j}}
\end{aligned}
$$

$A_{i j}$ stands for the gravity from hospital $\mathrm{j}$ to village $i . S_{j}$ stands for the size of hospital $\mathrm{j}$, which is the hospital's number of beds or the number of technical staff. $\alpha_{j}$ stands for the level of hospital $\mathrm{j}$, this is because the different levels of hospital service quality is different. We can use the expert scoring method to determine the $\alpha_{j .} d_{i j}^{\beta}$ stands for the cost which includes costs, times, distances from $i$ village to hospital. In this paper, it is stood for the shortest distance from village $i$ to hospital. For $\beta$ value Setting, according to the specific situation of the study area, in combination with related literature, taking $\beta=2$. $P_{i j}$ means the probability from village $i$ to hospital. $\sum_{j=1}^{n} A_{i j}$ means the sum of the gravity from village $i$ to each hospital.

$$
E_{j}=\sum_{i=1}^{m}\left(P_{i j} C_{i}\right)
$$

$E_{j}$ stands for the total population which hospital $j$ can service for in an administrative area. $C_{i}$ stands for the total population of village $i$.

In real life, we know that usually people affected by a number of factors when people consider which to choose, not just one single factor such as beds number or hospital staff number. In this paper we studied all the various hospital indicators to determine the weight of each indicator, then calculated the size of the hospital by using the weighted factors.

According to the introduction and establishment of Hoover model in the previous section, first, calculated the weight of each relevant hospital index, then collected the main indicators of a hospital, such as the actual number of beds, number of technical personnel, the total area of wards and the number of equipments. Used questionnaires to explore how people value those four indicators when they choose hospitals. Summarized the statistical results from the questionnaires. Calculated the weight for each indicator based on the 
questionnaire results: technical staff accounted for 0.4 , the number of beds accounted for 0.3 , equipment accounted for 0.2 , and housing area accounted for 0.1 . Hospital grades $\alpha \mathrm{j}$ information was mainly consulted the authorities and experts, four grades were divided: County People's Hospital was 4, the County Public Health Hospitals and Guyang Town Hospital were 3, County Hospital and Chengguan Town Hospitals were 2 and others were 1.

Use New Closest Facility in Network Analyst in ArcGIS 10.0 to find the closest distance from each villages to each hospital.

Built personal database by Office Access, imported the hospital grades table and the nearest distance map into the database, joined the table and the map to calculate the probability that each village may choose (Table 1).

Table1. Probability of 21 Villages to Hospitals

\begin{tabular}{|c|c|c|c|c|c|c|}
\hline Hospital & Zhanglou & Houzhai & $\ldots$ & Chendouzhai & $\ldots$ & Zhangdong \\
\hline Mengzhai & 0.000100277 & 0.000206 & & 0.000141 & & 0.000898 \\
\hline Xuhe & 0.000125583 & 0.00025 & & 0.000179 & & 0.001095 \\
\hline Yanlou & 0.000129933 & 0.000269 & & 0.00018 & & 0.003269 \\
\hline Xiaosong & 0.000216452 & 0.000445 & & 0.000305 & & 0.00349 \\
\hline Putaojia & 0.000237115 & 0.000446 & & 0.000323 & & 0.003838 \\
\hline Nanzhang & 0.000418815 & 0.000696 & & 0.000536 & & 0.004291 \\
\hline Guying & 0.000500518 & 0.000887 & & 0.000597 & & 0.004968 \\
\hline Batou & 0.000595858 & 0.000898 & & 0.000669 & & 0.006274 \\
\hline Yifeng & 0.000671615 & 0.001183 & & 0.00133 & & 0.006677 \\
\hline Zhuaoying & 0.001167453 & 0.001996 & & 0.001531 & & 0.0079 \\
\hline Hongmiao & 0.001302366 & 0.002225 & & 0.001707 & & 0.009237 \\
\hline Zhangjunmu & 0.001338359 & 0.002733 & & 0.001773 & & 0.009934 \\
\hline Guyang & 0.010041851 & 0.003155 & & 0.001881 & & 0.010609 \\
\hline Sanyizhai & 0.014566247 & 0.019354 & & 0.01317 & & 0.028766 \\
\hline Zhongyuan & 0.033728532 & 0.019814 & & 0.013805 & & 0.042546 \\
\hline Longan & 0.034164429 & 0.026664 & & 0.031294 & & 0.072621 \\
\hline Chengguan & 0.054664028 & 0.03025 & & 0.033506 & & 0.095884 \\
\hline Chengguan Town & 0.081472509 & 0.081919 & & 0.084869 & & 0.113659 \\
\hline County Hospital & 0.108013428 & 0.108075 & & 0.11226 & & 0.149845 \\
\hline Pubblic Hospital & 0.316200654 & 0.29232 & & 0.316591 & & 0.190206 \\
\hline People's Hospital & 0.340343978 & 0.406215 & & 0.383352 & & 0.233992 \\
\hline
\end{tabular}

Joint the Table1 and the village population table to calculate the population of each village to the hospital allocation table. Based on the hospital grades division, calculated the potential service population of each hospital. Under ideal conditions, the behavior of medical residents in the county was equal. Based on the previous research on the proportion between village total population and the total population visited to hospital per year, we got the proportion was 1.15 . The potential service population needed to multiply 1.15 to get a potential medical visit. Table 2 showed the ratio of the potential hospital visit to the actual hospital visit of each village.

Table 2. Ratio of Clinic Visits

\begin{tabular}{ccccc}
\hline Hospital & $\begin{array}{c}\text { Potential service } \\
\text { population }\end{array}$ & $\begin{array}{c}\text { Potential clinic } \\
\text { visits }\end{array}$ & $\begin{array}{c}\text { Actual clinic } \\
\text { visits }\end{array}$ & $\begin{array}{c}\text { Ratio of } \\
\text { clinic } \\
\text { visits }\end{array}$ \\
\hline Sanyizhai & 1699 & 1957 & 14000 & 7.1532 \\
Batou & 2650 & 3053 & 15000 & 4.9128 \\
Yanlou & 4049 & 4664 & 4600 & 0.9862 \\
Yifeng & 4746 & 5468 & 9000 & 1.6460
\end{tabular}




$\begin{array}{ccccc}\text { Mengzhai } & 4788 & 5516 & 10300 & 1.8673 \\ \text { Chengguan } & 5197 & 5987 & 9980 & 1.6669 \\ \text { Guying } & 7010 & 8076 & 10000 & 1.2382 \\ \text { Hongmiao } & 8306 & 9568 & 23400 & 2.4456 \\ \text { Putaojia } & 8391 & 9667 & 5000 & 0.5172 \\ \text { Xiaosong } & 11124 & 12814 & 9100 & 0.7101 \\ \text { Longan } & 11151 & 12846 & 12610 & 0.9817 \\ \text { Xuhe } & 12071 & 13906 & 4640 & 0.3337 \\ \text { Zhuaoying } & 12940 & 14907 & 7610 & 0.5105 \\ \text { Zhongyuan } & 19334 & 22273 & 47200 & 2.1192 \\ \text { Nanzhang } & 19647 & 22633 & 18560 & 0.8200 \\ \text { Chengguan } & 37697 & 43427 & 21000 & 0.4836 \\ \text { Town } & 57596 & 66351 & 39000 & 0.5878 \\ \text { County } & 59248 & 68254 & 26220 & 0.3842 \\ \text { Hospital } & 105913 & 122012 & 156100 & 1.2794 \\ \text { Zhangjunmu } & 115286 & 132810 & 41200 & 0.3102 \\ \text { Pubblic } & 237077 & 273112 & 375000 & 1.3731 \\ \text { Hospital } & & & & \\ \text { Guyang } & \text { People's } & & & \\ \text { Hospital } & & & \end{array}$

\section{Analysis of Calculation Results}

We can get the number of potential service population through calculation. By investigating on hospitals, it can be found between the annual visits of each hospital and the total population of the county there is a fixed ratio of 1.15. Potential trips for medical treatment can be resulted by the potential service population multiplied by 1.15 . Final ratio of clinic visits is that potential visits are divided by the actual medical trips. The result is demonstrated as the Figure 2 and Figure 3.

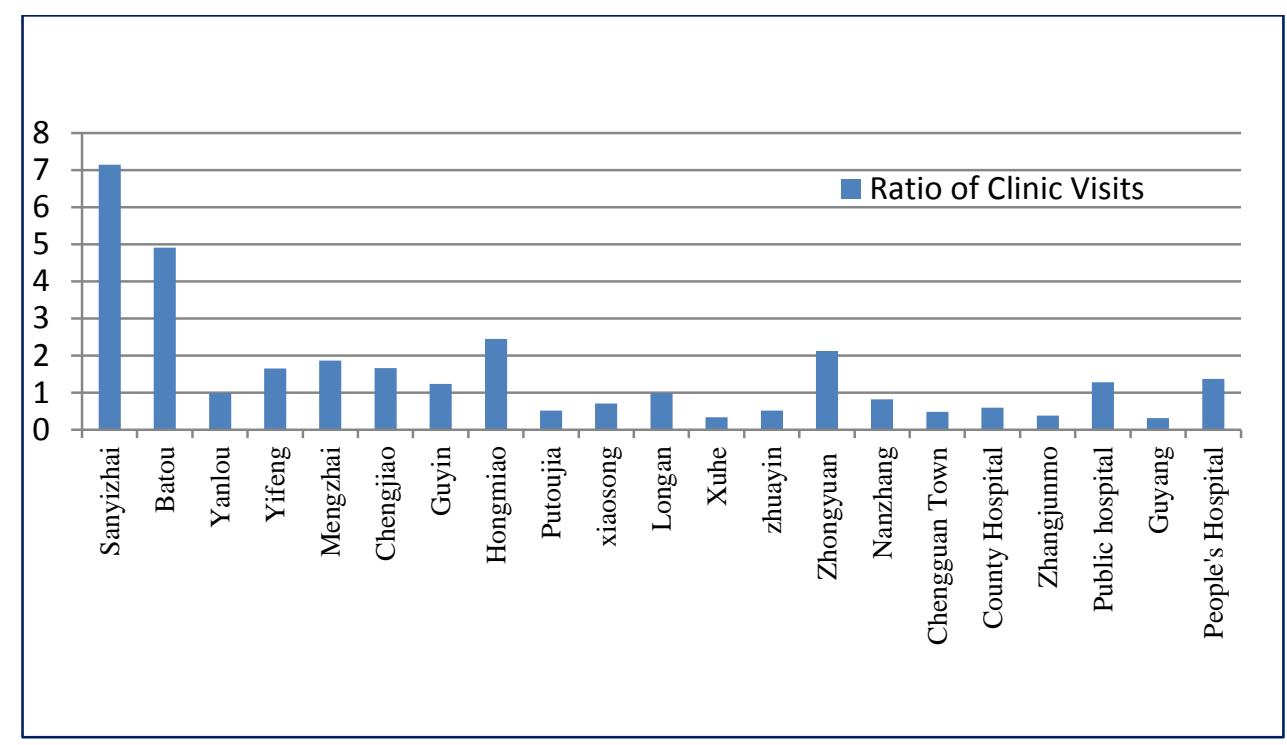

Figure 2. Ratio of 21 Hospitals Clinic Visits 


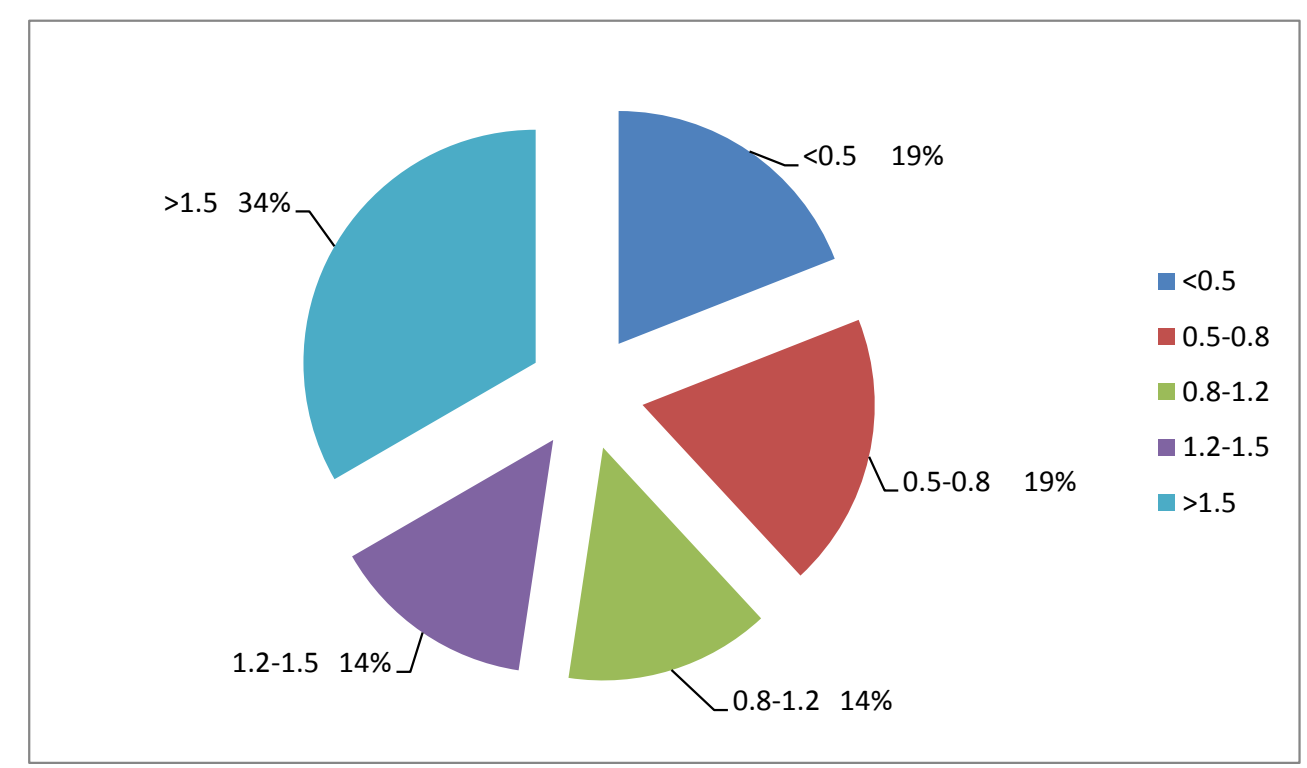

Figure 3. Distribution Statistic on Treatment Ratio of Hospitals Clinic Visits

By Figures 2 and combined with the expert recommendations we can see that only when a hospital clinic visits and potential visits ratio close to 1, the layout of the hospital is reasonable. 21 hospitals can be divided into five groups(Figure 3):

(1) The total of three hospitals whose ratios are between 0.8 and 1.2 are relative reasonable distribution.

(2) Hospitals total of four resources are waste, whose ratios are between 0.5 and 0.8 .

(3) It is excessive waste of resources that the ratio is less than 0.5. A total of four, the largest waste is Guyang hospital.

(4) The hospitals' resources are excessive use whose ratios are between 1.2-1.5.The number is three.

(5) Resources are very over-utilization using of which ratio above 1.5. A total of seven, Batou and Sanyizhai Village Health Center has been seriously overloaded operating.

According to the above calculation and Figure 2, although the calculation of the population of potential medical treatment according to the Hoover model, not only the capacity of hospital services and the level of hospitals but also the distance and the demographic factors around hospitals are taken into account. However, Figure 2 demonstrates the phenomenon that is unfair. It can't reach the ideal state. This situation is mainly determined by the hospitals' reputation and their quality of medical services, the level of economic development of the township, the development of private hospitals and other objective factors. The results also reflect that: medical planning system in rural areas is very imperfect, and medical facilities in rural areas is relatively uneven spatial distribution, two hospitals at the county level (County People's Hospital, the County Public Hospital) as well as several township hospitals are under enormous pressure, and the other hospitals can not take full advantage of the ability of medical services.

\section{Conclusions}

This paper studies and discusses the spatial distribution equity of the medical facilities in China. By using GIS technology and establishing Huff model for this research, we can draw the conclusions as follows: 
(1) We can see an uneven medical facilities spatial distribution in rural areas from the per capita distribution of health care resources, the access to medical care, and the comfort level in terms of medical care. In this research, local residents from more than 60 villages need to travel more than $10 \mathrm{~km}$ for hospitals. Within $10 \mathrm{~km}$, inhabitants from more than 190 villages only have one hospital can be reached. The number of their population reaches to $1 / 3$ of the total population of the county. Thus, many farmers can not have a good medical treatment because of the poor accessibility to hospitals.

(2) Established Huff model to calculate the distribution of the villagers' hospital choices, and then determine the efficiency of use of health resources and the relative problems. We used Huff model to calculate each hospital's potential visits. We compared the predicted visits with the actual visits in order to determine the efficiency of the use of medical resources. We found out many problems. Some hospitals had lower actual visit number than potential visits which indicated the poor quality medical services. It is difficult to attract more patients, resulting in a lower efficiency of medical resources. Some hospitals' actual visits were higher than the potential visits, this may be due to their good reputation. A large number of patient visits caused the over-exploitation of the medical resources in these hospitals. The main reasons are the medical resources excessive concentration on space and the difficulties for people to reach the hospital because of the long distance.

While considering the impact factors from various aspects, the quality of the obtained data may affect the results. The next step is to continue collecting more detailed and more reliable data and information through a few more field research. Choosing farmers/local residents' information as the impact factors should be considered too. Because their income and habits will influence their decisions on choosing hospitals.

\section{Acknowledgment}

This publication has been funded under the National Natural Science Foundation of China (41171439), The development program of science and technology of Henan (142400410684), The tender subject of government decision and study of Henan (2014207), Henan province social science research program (SKL-2014-3405) and Henan university natural science fund project(2013YBZR001). Its content does not represent the official position of the Chinese government and is entirely the responsibility of the authors.

\section{References}

[1] F. Liu and Y. Li, "Rural public health system to actively explore", Agricultural economy, vol. 74, no. 4, (2004), pp. 74-78.

[2] X. Li, "On the rational allocation of health resources in China", Chinese Health Economics, vol. 21, no. 2, (2002), pp. 1-6.

[3] $\mathrm{M} . \mathrm{Wu}, \mathrm{J} . \mathrm{Wu}$ and $\mathrm{C}$. Hu, "The city of fire station layout evaluation indicators Quantitative Analysis", Journal of Natural Disasters vol. 15, no. 5, (2006), pp. 162-167.

[4] G. Rushton, "Considerations for Improving Geographic Information System Research in Public Health", URISA, vol. 12, no. 5, (2000), pp. 31-49.

[5] E. K. Cromley and S. L. McLafferty, "GIS and Public Health", New York: GUILFORD , (2002), pp. 233-258.

[6] A. Eason and S. Tim, "Using GIS as a management tool for health care assessment and planning", Geographic Information Systems in public health: proceedings of the Third National Conference, (1998), pp. 299-310.

[7] G. Higgs, Sun, "Literature Review of the Use of GIS-Based Measure of Access to Health Care Services," Health Services \& Outcomes Research Methodology, vol. 5, (2004), pp. 119-139.

[8] D.L. Huff, "Don't misuse the Huff Model in GIS", Business Geographies, vol. 8, no. 8, (2000), pp. 12. 


\section{Authors}

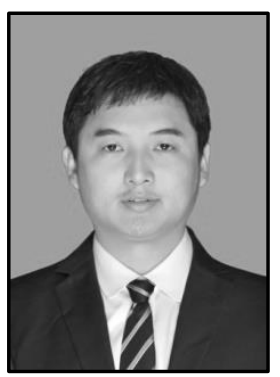

Pengyan Zhang, male, born in 1983, PhD, Associate Professor of Henan University, China. Research interests are regional land use and climate change. Published more than 20 papers, participated writing two books, hosted and participated several national and provincial projects. The main research are Dynamic changes and evaluation of ecological environment status based on GIS, the impact of climate change on land use / land cover, and the possible sensitivities of environmental changes on land use/land cover

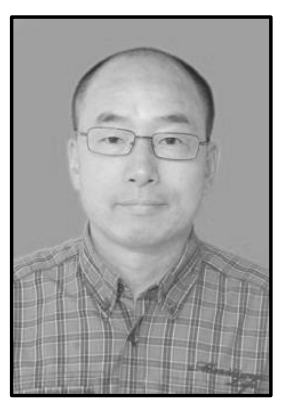

Youmin Chen, male, born in 1964, PhD, Professor of Henan University China. Research interests are regional model in climate change. 